\title{
NUTRIENT EFFECTS IN CONSUMER DEMAND SYSTEMS: EVIDENCE FROM PANEL DATA
}

\author{
B. Dhehibi \\ Laboratoire d'Economie Rurale \\ Institut National de la Recherche Agronomique de Tunisie \\ Rue Hedi Karray 2049 Ariana - Tunis. Tunisia \\ Phone: 216.71230024-Fax.: 216.71716537 \\ E-mail: bdhehibi@aragon.es \\ J. M. Gil \\ CREDA-UPC-IRTA \\ Edifici ESAB- Parc Mediterrani de la Tecnologia \\ Av. del Canal Olimpic, $\mathrm{s} / \mathrm{n}$ \\ 08860-Castelldefels (Barcelona-Spain) \\ Phone: 93 5521210- Fax: 935521121 \\ E-mail: chema.gil@upc.edu \\ A. M. Angulo \\ Departamento de Análisis Económico \\ Facultad de Ciencias Económicas y Empresariales \\ Gran Vía, 2, 50.005 Zaragoza (Spain) \\ Phone: 976761831 - Fax.: 976761996 \\ E-mail: aangulo@unizar.es
}

\begin{abstract}
This papers aims to analyse the demand for main food groups in Spain. Apart from the traditional economic factors (prices and income), our theoretical framework incorporates the nutrient composition of food into a demand model in the form of food attributes, as a proxy to take into account the rising consumer concern about the relationship between diet and health. A CBS functional form is chosen for the empirical model, which is estimated using a complete panel data set. Ten broad categories, nine nutrients and the most relevant socioeconomic variables have been considered. Finally, after employing an appropriate selection strategy, the chosen model is used to calculate expenditure, price and nutrient elasticities, as well as the main socio-demographic effects. Results indicate that the introduction of nutrientbased determinants generates elasticities that differ from those obtained when only economic factors are included, particularly in the case of price elasticities. As the nutrients effect is incorporated in the model through adjusted prices, unhealthier food groups (cereals, white meat and eggs, dairy and sugar) become more inelastic as they are associated with higher perceived prices.
\end{abstract}

KEY WORDS: Nutrients, Demand for Food, CBS, Panel Data, Spain. 


\section{NUTRIENT EFFECTS IN CONSUMER DEMAND SYSTEMS: EVIDENCE FROM PANEL DATA}

\section{INTRODUCTION}

A large body of scientific research has shown that diet plays an important role in determining the risk of chronic diseases such as coronary heart disease, cancer, stroke, diabetes, hypertension and osteoporosis. Apparently, consumers are paying attention. Food consumption patterns are increasingly being driven by a much more complex set of consumer-perceived food nutrition factors than economists have traditionally incorporated in demand studies.

Several studies based on time series data have already integrated certain types of health information indexes that are designed to measure the effect of consumer health concerns (Brown \& Schrader, 1990; Capps \& Schmits, 1991; Kinnucan et al., 1997; Chern \& Kim, 1999; Ben Kaabia et al., 2001; and, Rickertsen et al., 2003). When using cross section data, previous literature has introduced health concern through the consideration of nutrient intake, using two main approaches. In the first, the effects of income and sociodemographic variables are measured on the demand for nutrients (Adrian \& Daniel, 1976; Devaney \& Fraker, 1989; Nayga, 1994; Ramezani, 1995; Subramanian \& Deaton, 1996; or Chesher, 1998, among others). In the second, an indirect two-step process is employed. First, a food demand system is estimated in order to calculate the effects of the relevant variables. Then, the effects of nutrient intake are measured by applying nutrient conversion factors to the resulting food effects (Xiao and Taylor, 1995; Ramezani et al., 1995; and Huang, 1999).

However, we believe both approaches merely analyse the demand for nutrients instead of the demand for food. Since nutrients are not directly available in the market, the applicability of such results is limited. Hence, in this paper, we have incorporated the nutrient composition of food into a demand model in the form of food attributes. This enables us to measure quantitative changes in the demand for specific food products based on their nutritive attributes, rather than measuring nutrient demand in an isolated fashion. From the methodological point of view the consumer utility function is taken here to be a function of 
food attributes (where various nutrients form part of these attributes) and not a function of the goods themselves, following the consumer goods characteristics model approach introduced by Lancaster $(1966,1971)$. It is not unrealistic to assume that consumers are starting to think more in terms of food attributes than in terms of food products, while also taking into account prices and disposable income. The result is a demand function in which food quantities are considered as dependent variables, and income, prices and food attributes are the exogenous variables. Second, and with respect to our methodology, the $\mathrm{CBS}^{1}$ demand system proposed by Keller \& Van Driel (1985) is used as the functional form. Finally, the specified model is estimated over a panel data set using information provided by the Spanish Continuous Survey of Family Budgets (Encuesta Continua de Presupuestos Familiares, ECPF). Only food consumed at home is considered ${ }^{2}$.

The paper is structured as follows. We first present the evolution of the nutrient intake structure in Spain. Next, the theoretical foundations as well as the functional form of the model are developed. Then, Section 4 is devoted to the description of the panel data set. The econometric issues are outlined in Section 5, while in Section 6 our main results are presented. Finally, we draw our chief conclusions and indicate some interesting paths for extending the research on the role of nutrients in modern food demand.

\section{FOOD DEMAND STRUCTURE IN SPAIN}

So, what are Spaniards eating at home? We need this information to better understand the empirical results that follow. Table 1 shows the evolution of the nutrient intake structure from 1990 to 2002 for the various nutrients included in this paper (calories, carbohydrates, lipids, proteins, fibre, calcium, minerals, cholesterol and vitamins) and for the main food products. Two important observations on this data can be made. First, the relative importance of the different food groups in providing the different nutrients was quite stable over those twelve years. Second, as shown in the table, calories come mainly from cereals, potatoes and oils; carbohydrates come from cereals, potatoes and sugar; lipids from oils, dairy and red meat; proteins, from cereals, potatoes, dairy and meat; fibre intake comes from cereals,

\footnotetext{
${ }^{1}$ The name is taken from the institution in which they worked: the Dutch Central Bureau of Statistics.

${ }^{2}$ The relative importance of Food-Away-From-Home (FAFH) expenditure has continuously increased during the last ten years, representing, in 2002, around 25\% of total food expenditure in Spain (MAPA, several years). This relative importance substantially differs among food products, being especially important in the case of drinks (50\%). However, the data set used in this study does not provide information on quantities consumed and prices. Only expenditure information is included, making unfeasible to incorporating FAFH consumption in our model.
} 
potatoes, fruits and vegetables; calcium from dairy products; minerals, from cereals, potatoes and dairy products; cholesterol from eggs; and finally, vitamins are mainly coming from vegetables, dairy products and fruits.

(Insert Table 1)

We now explore possible differences in per capita nutrient intake introduced by four socio-economic scales. To this end, Table A1, in Appendix A, shows the evolution of nutrient intake at home per capita per day for the whole sample and for certain subgroups which reflect the main socio-economic characteristics of Spanish households: 1) the size of the town where the household lives; 2) the level of education of the head-of-household; 3) the age of the head-of-household; and 4) the composition of the household, measured by the percentage of members over 13 years of age.

(Insert Table A1)

Regarding population size, those living in the biggest cities (with more than 500,000 inhabitants) consume less of all the nutrients. And in general, as the size of the town increases, residents consume less carbohydrates, fibre and minerals. The next scale shows that as the level of education of the head-of-household increases, the total intake of lipids, carbohydrates and cholesterol decreases. One might conclude that higher-educated consumers choose healthier food products. But this result could also be explained by the fact that the educated population segment eats out more than the general population, and Table A1 only includes food consumed at home. This also helps explain why homes headed by a person who has not completed primary school have the highest intake for all nutrients.

The third scale shows that when the head-of-household is over 25 years of age, the intake of all nutrients increases as their head-of-household gets older. Finally, the maximum nutrient intake is found for households whose members over 13 years of age comprise between $50 \%$ and $75 \%$ of the total.

\section{MODEL SPECIFICATION}

\subsection{THEORETICAL MODEL}

Our theoretical approach starts by making the very plausible assumption that for more developed countries, consumer food choices are influenced by food attributes such as 
nutrients, taste, smell, appearance, etc ${ }^{3}$. The consumer goods characteristics model approach (Lancaster 1966, 1971) fits with this principal assumption.

Let us now assume that the vector $\phi=\left(\phi_{1} \ldots, \phi_{r}\right)^{\prime}$ represents the levels of $r$ attributes provided by the food products (nutrients, taste, smell, appearance, etc.). Of course, the components of $\phi$ are not directly sold in the market but they must be obtained using different types of inputs. Then, let $q=\left(q_{1} \ldots, q_{n}\right)^{\prime}$ represent the total set of food inputs available to the consumer, which can be bought in the market at prices $p=\left(p_{1} \ldots, p_{n}\right)^{\prime}$. In this study, the vector $\phi$ represents the new argument of the consumer utility function.

Households purchase market goods in quantities $q$ with the purpose of jointly producing $\phi$ which yields utility $U=U(\phi)$, where $U($ ) is assumed to be strictly quasiconcave. A linear relationship is assumed between $\phi$ and $q$ through the consumption technology matrix, A:

$$
\phi=A q
$$

where $A=\left[a_{k j}\right]$ is an $r \times n$ matrix of known elements, and where the $k^{\text {th }}$ row represents the amount of attribute $k$ provided by one unit of each of the $n$ food products. The $j^{\text {th }}$ column represents the amount of each of the $r$ attributes provided by one unit of the $j^{\text {th }}$ product ${ }^{4}$.

Finally, we must consider the consumer budget constraint:

$$
\sum_{j=1}^{n} p_{j} q_{j}=x
$$

with $x$ denoting total food expenditure.

Summarizing, the consumer choice problem is represented by the following optimization problem:

\footnotetext{
${ }^{3}$ Evidently, as suggested by one referee, the relative importance of these attributes on food choice may differ significantly among consumer segments.

${ }^{4}$ While matrix A can easily be defined for nutrients, this is not the case for the rest of attributes. This is a potential limitation.
} 


$$
\begin{aligned}
& \operatorname{Max} U\left(\phi_{1} \ldots, \phi_{r}\right) \\
& \text { subject to } \quad \text { i) } \sum_{j=1}^{n} p_{j} q_{j}=x ; \\
& \text { ii) } \phi_{k}=\sum_{j=1}^{n} a_{k j} q_{j} \\
& q_{j} \geq 0
\end{aligned}
$$

The Lagrangian function derived from (3) has the following form:

$$
L=U\left(\sum_{j=1}^{n} a_{1 j} q_{j} \ldots, \sum_{j=1}^{n} a_{r j} q_{j}\right)-\lambda\left(\sum_{j=1}^{n} p_{j} q_{j}-x\right)
$$

where $\lambda$ denotes the Lagrangian multiplier. Solving the first order conditions derived from (4), the general form of the demand equations satisfying (3) is:

$$
q_{i}=q_{i}\left(p_{1}, p_{2}, \ldots, p_{n}, a_{11}, \ldots, a_{1 r}, \ldots, a_{n 1}, \ldots, a_{n r}, x\right)
$$

A basic property of demand systems with attributes is that if the demand for any product increases as a result of a change in the demand for a particular attribute, the demand for the other products has to decrease, since total food consumer expenditures are constant. Following Barten (1977), it is important to note that, from a theoretical point of view, changes in $a_{j k}$ are only of interest in so far as they affect the first-order conditions derived from (4):

$$
\frac{\partial U}{\partial q_{h}}=\lambda p_{h}
$$

where, $\lambda=\frac{\partial U}{\partial x}$ is the marginal utility of income.

If the differentiation of the first-order condition with respect to $a_{j k}$ is multiplied by the Slutsky substitution effects matrix, the effect of attribute changes on consumption can be tied to the substitution effects of price changes as follows (Barten, 1977): 


$$
\frac{\partial q_{i}}{\partial a_{j k}}=-\left(\frac{1}{\lambda}\right) \sum_{h=1}^{n} s_{i h}\left(\frac{\partial\left(\frac{\partial U}{\partial q_{h}}\right)}{\partial a_{j k}}\right)
$$

where $s_{i h}=\frac{\partial q_{i}}{\partial p_{h}}+\left(\frac{\partial q_{i}}{\partial x}\right) q_{h}$ is the Slutsky substitution effect or the demand price slope where the utility is kept constant and, $v_{h j k}=\frac{\partial\left(\frac{\partial U}{\partial q_{h}}\right)}{\partial a_{j k}}$ is the effect of nutrient changes on marginal utility.

If both sides of equation (7) are multiplied by $\left(\frac{p_{i} q_{i}}{x}\right)\left(\frac{a_{j k}}{q_{i}}\right)$, the following expression is obtained:

$$
\left(\frac{p_{i} q_{i}}{x}\right)\left(\frac{\partial q_{i}}{\partial a_{j k}}\right)\left(\frac{a_{j k}}{q_{i}}\right)=-\sum_{h=1}^{n}\left(\frac{p_{i} p_{h}}{x}\right) s_{i h}\left[\frac{\partial\left(\frac{\partial U}{\partial q_{h}}\right)}{\partial a_{j k}}\right]\left(\frac{a_{j k}}{\lambda p_{h}}\right)
$$

or, in terms of budget shares $w_{i}=\frac{p_{i} q_{i}}{x}$ :

$$
w_{i}\left(\frac{\partial \ln q_{i}}{\partial \ln a_{j k}}\right)=-\sum_{h=1}^{n} \pi_{i h} \gamma_{h j k}
$$

where $\pi_{i h}=\left(\frac{p_{i} p_{h}}{x}\right) s_{i h}$ is the Slutsky coefficient and $\gamma_{h j k}=\frac{\partial\left[\ln \left(\frac{\partial U}{\partial q_{h}}\right)\right]}{\partial \ln a_{j k}}$ is the elasticity of the marginal utility for good $h$ with respect to attribute $k$ for food item $j$, using the firstorder condition (6) for utility maximization.

\subsection{FUNCTIONAL FORM}

With these theoretical foundations, and a few of its implications derived, we now need 
to choose a functional form for the empirical model. From the logarithmic differential version of Equation (5), we get ${ }^{5}$ :

$$
w_{i} d \ln q_{i}=\theta_{i} d \ln Q+\sum_{j=1}^{n} \pi_{i j} d \ln p_{j}+\sum_{j=1}^{n} \sum_{k=1}^{r} \beta_{i j k} d \ln a_{j k}
$$

where $\quad d \ln Q=d \ln x-\sum_{j=1}^{n} w_{j} d \ln p_{j}=\sum_{j=1}^{n} w_{j} d \ln q_{j} \quad$ is the Divisia volume index and $\beta_{i j k}=-\sum_{j=1}^{n} \pi_{i j} \gamma_{j j k}$

If parameters $\theta_{i}$ and $\pi_{i j}$ are assumed to be constant, the Rotterdam Model is obtained. However, there is no strong a priori reason for such restrictions. An alternative parameterization exists based on Working's Engel model, $w_{i}=\alpha_{i}+\beta_{i} \ln x$, from which it is possible to derive the marginal budget shares, $\theta_{i}$, by multiplying by $x$ and then differentiating with respect to $x$ :

$$
\begin{array}{cc}
\frac{\partial\left(p_{i} q_{i}\right)}{\partial x}= & \alpha_{i}+\beta_{i}(1+\ln x), \\
\text { or } \quad \theta_{i}=w_{i}+\beta_{i}
\end{array}
$$

Expression (10) implies that, under the Working's model, the $i^{\text {th }}$ marginal budget share differs from the corresponding budget share by $\beta_{i}$. Since the budget share is not constant with respect to income, neither is its associated marginal budget share. Substituting (10) in (9), we get the CBS model (Keller and van Driel, 1985) for the purpose of this paper:

$$
w_{i} d \ln q_{i}=\left(\beta_{i}+w_{i}\right) d \ln Q+\sum_{j=1}^{n} \pi_{i j} d \ln p_{j}+\sum_{j=1}^{n} \sum_{k=1}^{r} \beta_{i j k} d \ln a_{j k}
$$

Following Theil (1980) and Duffy (1987, 1989, 1990), we assume that $\beta_{i j k}=-\pi_{i j} \gamma_{j j k}$ and we let $\gamma_{j j k}=\gamma_{j k}$. The resulting demand system is given by:

\footnotetext{
${ }^{5}$ See the Appendix B.
} 


$$
\begin{aligned}
w_{i} d \ln q_{i} & =\left(\beta_{i}+w_{i}\right) d \ln Q+\sum_{j=1}^{n} \pi_{i j}\left(d \ln p_{j}-\sum_{k=1}^{r} \gamma_{j k} d \ln a_{j k}\right) \\
& =\left(\beta_{i}+w_{i}\right) d \ln Q+\sum_{j=1}^{n} \pi_{i j} d \ln p_{j}^{*}
\end{aligned}
$$

where $\gamma_{\mathrm{jk}}$ represents the elasticity of marginal utility with respect to attribute $k$ in food $j$.

In equation (12), $\gamma_{\mathrm{jk}}$ will be non-negative if attributes increase consumer utility. In addition, the term $d \ln p_{j}^{*}=d \ln p_{j}-\sum_{k=1}^{r} \gamma_{j k} d \ln a_{j k}$ can be considered as the modified price for food item $\mathrm{j}$ taking into account the attribute composition of each food group. This term is also known as the perceived price for food item $j$. The impact of a change in $a_{j k}$ on $p_{j}^{*}$ can be expressed as $\frac{\partial d \ln p_{j}^{*}}{\partial d \ln a_{j k}}=-\gamma_{j k}$.

Note that, if $\gamma_{j k}>0$, then an increase in attribute $k$ in food $j$ decreases the price perceived by the consumer for food item $j$, which will probably increase the demand for this food item. Similarly, if $\gamma_{j k}<0$, then an increase in attribute $k$ will increase the perceived price for the food item $j$ and will probably decrease the demand for it.

Finally, it is possible to include in (12), as in any other demand system, an intercept $\alpha_{\mathrm{i}}$ designed to represent changes in consumer taste. The final model, then, becomes:

$$
w_{i} d \ln q_{i}=\alpha_{i}+\left(\beta_{i}+w_{i}\right) d \ln Q+\sum_{j=1}^{n} \pi_{i j} d \ln p_{j}^{*}
$$

CBS is a flexible demand system in which economic theory restrictions can easily be imposed on its parameters. In our case we know that: the adding-up restrictions are $\sum_{i=1}^{n} \alpha_{i}=0, \sum_{i=1}^{n} \beta_{i}=1$ and $\sum_{i=1}^{n} \pi_{i j}=0 ;$ homogeneity necessitates that $\sum_{j=1}^{n} \pi_{i j}=0 ;$ and symmetry demands that $\pi_{i j}=\pi_{j i}$. Finally, the negativity condition obliges $\varpi^{\prime} \pi \varpi \leq 0 \quad \forall \quad \varpi \neq 0$, indicating that the matrix $\pi$ must be negative semi-definite and of rank $n$ - 1 . The negativity condition implies that the eigenvalues of the $\pi$ - matrix must all be non-positive. Since the rank of $\pi$ is $(n-1)$, the negative semi-definite condition requires the eigenvalues to be zero in 
one case, and then contain (n-1) negative values. For our situation, the negativity condition cannot be tested statistically; however, the eigenvalues of the parameter matrix can be used to indicate whether this condition holds, on the average.

The expenditure, price and attribute elasticities corresponding to the CBS model (13) are given by:

- Expenditure elasticities: $\quad \eta_{i}=\frac{\beta_{i}+w_{i}}{w_{i}}$

- Uncompensated own-price elasticities: $\mu_{i i}=\frac{\pi_{i i}-\left(\beta_{i}+w_{i}\right) w_{i}}{w_{i}}$

- Uncompensated cross-price elasticities: $\mu_{i j}=\frac{\pi_{i j}-\left(\beta_{i}+w_{i}\right) w_{j}}{w_{i}}$

- Compensated own-price elasticities: $\quad e_{i i}=\frac{\pi_{i i}}{w_{i}}$

- Compensated cross-price elasticities: $\quad e_{i j}=\frac{\pi_{i j}}{w_{i}}$

- Attribute elasticities:

$$
\xi_{i j k}=\frac{-\pi_{i j} \gamma_{j k}}{w_{i}}
$$

\section{DATA AND PRELIMINARY TRANSFORMATIONS}

The data comes from the Spanish Continuous Survey of Family Budgets (Encuesta Continua de Presupuestos Familiares, ECPF), which is conducted by the Spanish National Office of Statistics (Instituto Nacional de Estadística, INE). The ECPF is conducted every quarter with approximately 3,200 households participating. One eighth of the sample is renewed quarterly and hence an individual can be followed for a maximum of eight quarters (two consecutive years). Nevertheless, there is a significant percentage of households that do not complete all eight interviews (Browning \& Collado, 1999). In this study, a complete panel data set has been constructed by "following" those households that remain in the sample from the first quarter of 2001 through the fourth quarter of 2002. Additionally, those 
households that report zero expenditure in all food groups or in all groups but one were dropped from the sample. As a result, we were able to collect information on expenditure and quantities consumed of different food products ${ }^{6}$ from a total of 217 households during 8 quarters, which gives a total of 1,736 observations.

Food products have been aggregated into ten broad groups: 1) cereals and potatoes; 2) red meat (beef and pork); 3) white meat (poultry) and eggs; 4) fish; 5) dairy products; 6) oils; 7) fruits; 8) vegetables; 9) sugar and soft drinks; and 10) alcoholic beverages. This aggregation scheme groups together foods of similar nutrient composition.

As regards food attributes, while it is possible to measure nutrient intake by applying conversion factors to the consumed quantities, it is impossible to measure the rest of the perceived food attributes such as taste, smell or appearance. Hence, to be consistent with previous literature ${ }^{7}$, we have assumed that differences in taste and in other non-observable attributes are mainly represented by differences in household characteristics, which will be included in the model using the intercept term. So, we are following the translating approach proposed in Pollak and Wales (1981) where the $\alpha_{i}$ term in (13) is substituted by the following:

$$
\alpha_{i}^{*}=\alpha_{i}+\sum_{s} o_{i s} V S_{s}
$$

where $V S$ represents the socio-economic characteristics that exert a significant effect on food demand. Four factors have turned out to be important: the size of the town where the household lives, both the level of education and the age of the head-of-household and, finally, the percentage of members over thirteen years old in the household. On the other hand, sex, the number of earners in the household and the type of household (single, couple, ...etc) have not found to be significant on the Spanish demand for food.

Regarding nutrient content, $a_{j k}$ is defined as the average yearly nutritional content per unit of food consumed. This is calculated by dividing the total amount of nutrients by the

\footnotetext{
${ }^{6}$ Data on expenditure was available for all items within each food group or category. However, data on quantities was not available for all items. Within each group we were able to account for quantities that correspond to the following percentage of total expenditure for that group: cereals and potatoes, 58.63\%; red meat, 52.51\%; white meat and eggs, $66.87 \%$; fish, 60.52\%; dairy, 72.56\%; oils, 83.09\%; fruits, $86.05 \%$; vegetables, $69.24 \%$; sugar, $100 \%$; alcoholic beverages, $76.66 \%$.

${ }^{7}$ See the discussion on this topic in Gao at al. (1997a).
} 
quantity of food consumed. In this paper, the Andújar et al. (1983) nutrient conversion tables have been used to calculate these coefficients ${ }^{8}$. The following nutrients have been included: calories (kilocalories), carbohydrates (grams), lipids (grams), proteins (grams), fibre (grams), calcium (milligrams), others minerals (milligrams), cholesterol (grams) and vitamins (milligrams) ${ }^{9}$.

Finally, since prices are not recorded, unit values for each group are calculated by dividing expenditures by quantities. These values may reflect not only spatial variations caused by supply shocks (i.e., transportation costs, cost of information, seasonal variations, etc.) but also differences in quality which can be attributed to brand loyalty or marketing services, among other factors (Cramer, 1973; Cox \& Wohlgenant, 1986). For this reason, unit values must be adjusted before using them in the demand analysis (Cowling \& Raynor, 1970; Deaton, 1988). Following Gao et al. (1997b), the quality-adjusted price is defined as the difference between the unit price and the expected price, given its specific quality-related characteristics $^{10}$. The expected price is calculated by a hedonic price function such that:

$$
U V_{j}=\vartheta_{j}+\sum_{s} l_{s} V_{j s}+\varepsilon_{j}
$$

where $U V_{j}$ is the unit value and $V_{j s}$ are the variables affecting the consumer choice of qualities, such as income and household characteristics, which are used as proxies for unobservable household preferences regarding the quality of the good. Regional and seasonal dummy variables have not been included because although they reflect systematic supply variations, their average effects are reflected by the intercept $\vartheta_{j}$. Putting all this together, the quality-adjusted price is then:

$$
p_{j}=U V_{j}-\sum_{s} \hat{\imath}_{s} V_{j s}=\hat{\vartheta}_{j}+\hat{\varepsilon}_{j}
$$

\footnotetext{
8 Note that the $a_{j k}$ coefficients vary from household to household, since the composition of food products integrating each food group is different. For instance, although two households can consume the same quantity of fruits, nutrient content per unit of product, $a_{j k}$, can differ between them due to the different types of consumed fruits.

${ }^{9}$ We have calculated correlations among the different nutrient levels provided by each unit of food product. In all cases, correlation coefficients were lower than 0.6. Hence, we conclude that our choice of nutrients was appropriate.

${ }^{10}$ In those cases where unit values do not exist, as when households do not buy the specific product, these values have been estimated using a regression on the observed unit values of households which actually buy the product on dummy variables reflecting household characteristics such as region, season and income. The estimated parameters are then used to predict unit values for a specific household.
} 


\section{ECONOMETRIC SPECIFICATION AND ESTIMATION PROCEDURE}

With the theoretical framework and available panel data set complete, it is time to determine the appropriate econometric specification of the model. For a panel data set, the CBS demand system is given by:

$$
w_{i m t} d \ln q_{i m t}=\alpha_{i}^{*}+\left(\beta_{i}+w_{i m t}\right) d \ln Q_{m t}+\sum_{j=1}^{n} \pi_{i j} d \ln p_{j t}^{*}+\mu_{i m}+v_{i m t}
$$

where $w_{i m t}$ and $q_{i m t}$ are the budget share and the quantity of good $i(i=1, \ldots, n)$, for a household $m(m=1, \ldots, M)$, at time $t(t=1, \ldots, T) ; p_{j t}^{*}$ is the perceived price of good $j$ at time $t$; $\mu_{\text {im }}$ represents the household-specific effects, which can be modelled either as fixed (obtaining a fixed-effect model) or random (resulting in a random-effect model). Finally, the term $v_{i m t}$ represents the conventional error term. In this paper, we have assumed a random effect model as the starting point, which we will retain if specification tests do not provide evidence in favour of the fixed effect model. Next, we will outline the estimation procedure.

Under the assumption of random unobserved effects, the CBS model (23) must be carried out using a generalized least-squares estimator method due to the non-scalar nature of the covariance matrix of the error term $\left(\mu_{i m}+v_{i m t}\right)$. Using $\Sigma_{\mu}$ and $\Sigma_{v}$ to represent the different equation covariance matrices related to the error terms $\mu$ and $v$, the covariance matrix for the complete model adopts the following form (Baltagi, 2001):

$$
\Omega=\Sigma_{1} \otimes P+\Sigma_{v} \otimes Q
$$

where $\Sigma_{1}=T \Sigma_{\mu}+\Sigma_{v} ; P$ is a matrix that averages the observations over time for each household; and $Q$ is a matrix that obtains deviations from the household mean.

Finally, the generalized least-squares estimator of $\delta$ is obtained by:

$$
\hat{\delta}_{G L S}=\left(Z^{\prime} \Omega^{-1} Z\right)^{-1} Z^{\prime} \Omega^{-1} Y
$$

where $Y$ is the vector of the endogenous variables, $Z$ is the matrix of the exogenous variables and the inverse of the covariance matrix can be calculated as follows: $\Omega^{-1}=\Sigma_{1}^{-1} \otimes P+\Sigma_{v}^{-1} \otimes Q$. 
In order to obtain a feasible generalized least-squares estimator of $\delta, \Sigma_{1}$ and $\Sigma_{v}$ have to be estimated. We have used the procedure suggested by Wallace and Hussain (1969) which generates a consistent estimator of $\Sigma_{v}$ while the estimator of $\Sigma_{\mu}$ has a finite positive limit. Under such conditions, the feasible estimator (25) is asymptotically efficient (Prucha, 1984).

\section{RESULTS}

As mentioned in the previous section, we started by estimating a system (23) assuming random unobserved household-specific effects ${ }^{11}$. Theoretical restrictions (homogeneity and symmetry) were imposed, and the adding-up restriction then required us to drop one equation from the system to avoid the covariance matrix singularity problem. In our case, the "alcoholic beverages" equation has been taken out ${ }^{12}$. Finally, the negativity condition was checked after estimation, observing the signs of the $\pi_{i j}$ matrix eigenvalues. Since all the obtained values were non-positive, the condition is satisfied and, hence, it is not necessary to impose it.

Additionally, according to the existing empirical literature, equation by equation misspecification tests related to the error terms have been carried out on the estimated model. More precisely, the null hypotheses of homoscedasticity and no autocorrelation of error terms were tested. As regards homoscedasticity, White test results show evidence of heteroscedaticity problem in two out of the nine equations. Therefore, the robust t-ratios proposed by White (1980) have been calculated for all equations.

To detect any autocorrelation misspecification, the two types of statistics proposed by Bera et al. (2001) have been used. The first battery $\left(R S_{\mu}\right)$ tests the existence of serial correlation under a random effects model, while the second $\left(R S_{\mu \rho}\right)$ tests both the joint specification of a random effects model and that of no autocorrelation. Both statistics are

\footnotetext{
${ }^{11}$ The Times Series Processor (TSP) software has been used to make all the econometric work.

12 The eliminated equation parameters are obtained from the adding up conditions.
} 
distributed as a $\chi^{2}$ with 1 and 2 degrees of freedom, respectively. The results obtained from both tests indicate that the null of no autocorrelation is never rejected ${ }^{13}$.

While autocorrelation tests give us some statistical evidence in favour of the random effects model, the Hausman (1978) test has been used to corroborate this conclusion. As expected, the Hausman statistic was under the critical value $\left(252.35\right.$ again a $\chi_{0.05}^{2}(237)=$ 273.91). Hence, the null hypothesis could not be rejected and the random effect estimator is preferred over the fixed one.

Next, we tested for the presence of severe multicolinearity. The conditional value related to the correlation matrix of exogenous variables is 8.02 , which is under the critical value of 25 (Novales, 1997). Hence, multicolinearity is not a severe problem in our system.

Finally, the system goodness-of-fit has been assessed by calculating the system $\mathrm{R}^{2}$ proposed by Bewley \& Young (1987). In our case, the system $\mathrm{R}^{2}$ is 0.48 , which is relatively high if one takes into account that the dependent variable is defined in first differences. Furthermore, to measure the explicative power of nutrients, the analogous measure was calculated from a model without nutrients. In this case, the $\mathrm{R}^{2}$ takes on the value of 0.39 , indicating that incorporating nutrient intake variables significantly increases the explicative power of the model.

From the estimated parameters ${ }^{14}$, all elasticities (expenditure ${ }^{15}$, price and nutrient) are calculated. For comparison purposes, elasticities from the model without nutrients ${ }^{16}$ have also been calculated. Expenditure and uncompensated own-price elasticities, calculated at mean values, are shown in Table 2. All expenditure elasticities are positive and significant at the $5 \%$ level of significance. Red meat, oils, fruits, vegetables and alcoholic drinks are luxury goods (when total food expenditure increases, the allocation for these products increases more than proportionally). Elasticities for white meat and eggs, and fish are close to unity

\footnotetext{
${ }^{13}$ The values obtained for the $R S_{\mu}$ statistic for the 10 equations were: cereals and potatoes $(0.72)$; red meat (1.04); white meat and eggs (1.61); fish (2.09); dairy (1.47); oils (0.70); fruits (0.95); vegetables (2.23); sugar (1.77); and alcoholic beverages ( 0.18$)$ : all of them are under the critical value at $5 \%$ significance of 3.84 . The values obtained for the $R S_{u \rho}$ statistic for the 10 equations were: cereals and potatoes (2.23); red meat (3.71); white meat and eggs (2.45); fish (3.12); dairy (2.92); oils (3.89); fruits (4.47); vegetables (3.27); sugar (2.68); and alcoholic beverages (3.17): all of them are under the critical value at $5 \%$ significance, which is 5.99 .

${ }^{14}$ Not included, but available from authors.

${ }^{15}$ Since weak separability has been imposed, income elasticities have been calculated with respect to total food expenditure.

${ }^{16}$ That is, the random effects model associated with imposing in (22) the restrictions: $\ln p_{j t}^{*}=\ln p_{j t} \quad \forall j$
} 
(0.90 and 0.93, respectively). These results are quite consistent with expectations. Perhaps, in the case of red meat, fish and dairy one would expect higher values because these products are typically high-priced. However, as mentioned in footnote 3 , it is necessary to bear in mind that within each group, some of the most expensive products have not been included due to the lack of data. In fact, in the case of red meat, mutton is not included and, in the case of dairy, only fresh milk and sterilized milk are included, excluding high value-added products such as cheese and other dairies. For fish, only hake and whiting (fresh and frozen) have been included, both relatively low-price products. Finally, we observe that incorporating nutrient intake information slightly increases expenditure elasticities for the different food groups with the only exceptions being that of cereals and potatoes, white meat and eggs, fish and dairy. Nevertheless, the relative magnitude of elasticities for the different food groups does not change.

\section{(Insert Table 2)}

All uncompensated own-price elasticities are negative and significant. In general terms, the demand for the different products are quite inelastic; the most elastic products are fruits, cereals and potatoes, dairy and red meat. Comparison between these elasticities and those obtained from a model without nutrient attributes shows that, in most cases (cereals, white meat and eggs, dairy, fruits and sugar), the incorporation of nutrients into the specification of the demand system significantly reduces price elasticities. For the rest of the food groups, differences are not statistically significant, except in the case of fish where the price elasticity increases. Since the nutrients effect is incorporated in the model through adjusted prices that take into account the attribute composition of each food group (i.e. we are considering the perceived price for each food item), lower (higher) own-price elasticities are associated with higher (lower) perceived prices.

Finally, food demand elasticities with respect to a change in nutrient composition, nutrient elasticities, have been calculated. Note that nutrient effects are perceived through food prices. In other words, given how the model has been specified, a positive elasticity means that an increase in the quantity of the $i$-th attribute per unit of the $j$-th food product decreases the price perceived by the consumer for food item $j$, which will consequently increase the demand for that food item. Own and cross-nutrient elasticities (similarly to price elasticities) have also been calculated. In fact, taking into account the properties of the theoretical model, an increase in the cholesterol level contained in white meat and eggs, for 
example, will have a double consequence: one on the quantities demanded for such products (own-effect) and another on the quantities demanded for the other products (cross-effect). Nevertheless, our main attention will be paid to own effects ${ }^{17}$.

Own-nutrient elasticities for several products are considerably high (Table 3). However, the magnitude of such elasticities has to be interpreted with caution and it would be very risky to address a direct interpretation of the numeric values ${ }^{18}$. The reason for such high values is related to both model specification and data assumptions. In fact, as mentioned in footnote 8 , as conversion factors are assumed to be constant for the different products, its variability comes from the different composition of food products integrating each food group. Obviously, if some food group is only composed by two o three products (i.e. white meat and eggs, dairy, oils and sugar), inter-household variability is relatively small. As the model is specified in first differences, the estimated parameters associated with such conversion factors (and the corresponding elasticities) are relatively high, as can be observed in Table 3. As a result, we are going to concentrate our interpretation on the sign and the significance of the obtained elasticities.

The demand for cereals and potatoes is quite inelastic to various nutrient changes. That is, a per-unit change in the nutritive content of these foods does not produce an important change in demand for them. The only exception comes from the vitamin content, which exerts a negative effect on the demand for these two products. In the case of red meat and white meat and eggs, changes in calorie, lipid and the cholesterol content exert a significant and negative effect on the quantities demanded, while changes in protein content have a positive effect. Fish demand is positively affected by changes in carbohydrates, lipids, cholesterol, calcium and protein content while it is negatively affected by changes in calories and other mineral content. Dairy consumption is positively affected by changes in the vitamin content while negatively affected by changes in lipids, proteins and minerals. Oils are negatively affected by changes in the lipids content, while the effect of calories is positive.

\footnotetext{
${ }^{17}$ Intuitively, it should be an upper limit to nutrient intake. If this were true, any increase in the nutrient content of a product should decrease the demand for other products that incorporate that same nutrient. However, as food products can be eaten mixed in different combinations, it is difficult to set those upper limits. Hence, cross-elasticities can be positive or negative, but the interpretation will depend on the reader's intuition.

${ }^{18}$ However, this limitation, in our opinion, does not invalidate the suggested approach as it can be easily overcome with a richer data set.
} 
For fruits and vegetables, Table 3 shows that the demand for such products is positively and strongly influenced by changes in the vitamin content. Finally, carbohydrates positively affect the demand for sugar, while calories have a negative effect.

\section{(Insert Table 3)}

In general terms, if we analyse Table 3 by rows (from a nutrient intake perspective), an increase in a specific nutrient increases the demand for those products that are the main providers of that specific nutrient (taking into account their respective conversion factors). If one single product is by far and away the main provider for a nutrient, a negative sign is likely to appear for the rest of the main food group providers of that nutrient. A good example is calories. As can be observed, an increase in calorie content increases the demand for oils, but reduces the demand for sugar and meat (taking into account Andújar et al. (1983), 100 grams of oils generate $899 \mathrm{Kcal}$ while 100 grams of sugar and meat generate less than $25 \%$ of oil Kcal - 206 and $232 \mathrm{Kcal}$, respectively). An increase in carbohydrate content increases the demand for sugar (by far the main provider) and an increase in protein content increases the demand for meat and fish. This pattern can also be observed for vitamins and calcium. However, the results for minerals, lipids and cholesterol are not very conclusive. In the case of cholesterol and lipids, results are almost identical; indicating that maybe only one nutrient should be considered. Moreover, it would have been useful to distinguish between "good" and "bad" fats but Andújar et al (1983) does not provide such information.

Finally, let us find out how food demand is affected by the main socio-demographic variables. The results are shown in Table 4. First, remember that the reference category is populated by households living in towns with less than 10,000 inhabitants, headed by a 18 to 25-year-old person that has not completed primary school and, finally, with a percentage of members over thirteen years old that is less than $25 \%$.

\section{(Insert Table 4)}

We start by asking, what is the effect of the town size? Households living in the smallest towns (reference category) have the highest expenditures for red and white meat, dairy and other products, and the lowest for sugar. The highest expenditure share for cereals and potatoes corresponds to households living at the two extremes, the largest and the smallest towns. Allocations for fish and fruits are higher for households living in the middle 
size towns (from 10,001 to 500,000). Finally, note that the lowest oils and vegetables shares are for households living in towns between 50,001 and 500,000 inhabitants.

The level of education also plays an important role explaining differences in food consumption among Spanish households. Table 4 shows that, generally, as the level of education of the head-of-household increases, the cereals and potatoes expenditure share decreases. Also, households headed by a more-educated person (with at least secondary school under their belt) allocate higher expenditure shares for red meat, fish and other products, while spending less on white meat, dairy and vegetables.

Regarding the age of the head-of-household, the reference 18 to 26-year-old group has the highest expenditure shares for red meat, white meat and eggs, and for sugar, but the lowest for cereals and potatoes, dairy, oils, fruits and alcoholic beverages. The highest fish shares are for households headed by a person older than 46. Dining room tables of middle age heads-of-household (between 26 and 65 years old), have the smallest offering of vegetables.

Finally, we look at the effect of household composition, as measured by the percentage of members over thirteen years old. In general, as the household composition ages, we have an increase of red meat, fish, dairy and oils consumption, and a decrease of cereal and potatoes, white meat and eggs, fruits, vegetables and sugar.

\section{CONCLUDING REMARKS}

In most developed countries economic variables as food demand determinants are becoming less important while certain characteristics related to health issues are gaining in importance. Consumers have started to think more in terms of nutrients than in terms of the food products themselves (although, obviously, without ignoring the economic factors). In this paper we proposed a theoretical model based on the assumption that utility depends on food attributes (where nutrients are a subset of these attributes) instead of goods. From this theoretical model, we estimate a demand system that includes the nutritive content of food. While this type of analysis, as most of the empirical literature on food demand dealing with broad food groups and not with specific food products, may be limited interest for product development or agricultural marketing, our approach is able to provide more accurate food 
demand elasticities, which can be useful for policy analysis and general equilibrium modellers.

Results obtained in this paper are quite consistent with previous expectations. Moreover, the introduction of nutritive content in the utility function generates some differences in food demand elasticities compared to a model in which only prices and income are considered. These differences are most evident in the price elasticities. In fact, the incorporation of nutrient composition, in most cases, increases the perceived price of a specific food product, thereby reducing price elasticities. In the case of expenditure elasticity, the opposite takes place, that is, elasticities are higher when nutrients are incorporated although only slight differences are observed in this case. The only exceptions to this are found for cereals and potatoes, white meat and eggs, fish and dairy. We therefore conclude that the nutritive content of food products mainly affects the consumer demand for food through changes in the perception of the relationship between each product's quality and price. As mentioned above, this approach also has allowed us to calculate the nutrient elasticities. Our most fascinating result is this: specific food products that have been pegged in the mind of consumers as the principal source of a particular nutrient have their perceived value increased when they contain more of that nutrient. Meanwhile, competing, let us say "non traditional" sources of that same nutrient suffer the opposite effect.

This promising approach to including nutrients as food attributes shows that further research is needed in several areas. From a methodological point of view, it would be great to know how sensitive these results are to the selection of the functional form of the demand system. Of course, any new competing model should include alternative or complementary variables that take into account for the increasing consumer concern about the relationship between food and health. From an empirical point of view, one should be able to select the most relevant nutrients from a balanced diet point of view, to differentiate between "positive" and "negative" nutrients by, for instance considering deviations from official health department recommendations, and, finally, to be able to work with more specific and homogeneous food groups: red meats, oils, etc. 


\section{APPENDIX A}

TABLE A1. EVOLUTION OF AT-HOME NUTRIENT INTAKE OF DIFFERENT NUTRIENTS FOR DIFFERENT SOCIODEMOGRAPHIC CHARACTERISTICS (UNITS PER CAPITA AND PER DAY)

\begin{tabular}{|c|c|c|c|c|c|c|c|c|c|c|}
\hline & & $\begin{array}{c}\text { CALORIES } \\
\text { (KCAL) }\end{array}$ & $\begin{array}{c}\text { CARBOHY- } \\
\text { DRATES (GR) }\end{array}$ & $\begin{array}{c}\text { LIPIDS } \\
(\mathrm{GR})\end{array}$ & $\begin{array}{l}\text { PROTEINS } \\
(\mathrm{GR})\end{array}$ & $\begin{array}{l}\text { FIBRE } \\
(\mathrm{GR})\end{array}$ & $\begin{array}{c}\text { CALCIUM } \\
\text { (MG) }\end{array}$ & $\begin{array}{l}\text { MINERALS } \\
(\mathrm{MG})\end{array}$ & $\begin{array}{c}\text { CHOLES- } \\
\text { TEROL (MG) }\end{array}$ & $\begin{array}{l}\text { VITAMINS } \\
\text { (MG) }\end{array}$ \\
\hline \multirow[t]{3}{*}{ Total Sample } & 1990 & 2146.5 & 236.0 & 104.5 & 62.3 & 15.7 & 611.0 & 255.5 & 323.2 & 936.3 \\
\hline & 1998 & 2043.9 & 220.7 & 101.1 & 62.0 & 15.0 & 623.3 & 246.1 & 305.5 & 950.9 \\
\hline & 2002 & 2014.2 & 207.3 & 106.0 & 59.4 & 14.6 & 628.6 & 240.4 & 272.2 & 966.6 \\
\hline \multicolumn{11}{|c|}{ SIZE OF THE TOWN } \\
\hline$<$ Than 10,000 & 1990 & 2523.0 & 277.9 & 123.1 & 68.3 & 17.2 & 663.7 & 284.3 & 337.7 & 965.4 \\
\hline \multirow[t]{2}{*}{ inhabitants } & 1998 & 2357.5 & 255.8 & 116.2 & 69.6 & 16.4 & 682.4 & 274.2 & 332.8 & 991.4 \\
\hline & 2002 & 2276.4 & 229.7 & 122.6 & 64.2 & 15.7 & 661.0 & 258.9 & 295.9 & 1024.0 \\
\hline \multirow[t]{3}{*}{$10,001-50,000$} & 1990 & 2133.7 & 244.9 & 100.3 & 61.4 & 15.8 & 583.7 & 256.4 & 318.6 & 895.3 \\
\hline & 1998 & 2006.7 & 225.8 & 96.0 & 60.2 & 15.0 & 588.4 & 242.1 & 288.4 & 913.3 \\
\hline & 2002 & 2066.1 & 222.4 & 104.8 & 61.0 & 14.9 & 629.3 & 249.6 & 271.8 & 918.4 \\
\hline \multirow[t]{3}{*}{$50,001-500,000$} & 1990 & 1894.9 & 210.8 & 90.4 & 58.4 & 14.5 & 590.8 & 236.9 & 313.2 & 901.9 \\
\hline & 1998 & 1868.0 & 197.9 & 93.6 & 58.0 & 14.2 & 606.8 & 232.2 & 291.3 & 936.1 \\
\hline & 2002 & 1876.9 & 194.5 & 97.8 & 57.4 & 14.1 & 622.5 & 231.5 & 268.1 & 955.9 \\
\hline \multirow[t]{3}{*}{$>500,000$} & 1990 & 1987.7 & 194.2 & 107.0 & 60.7 & 15.1 & 590.7 & 238.6 & 324.3 & 1027.9 \\
\hline & 1998 & 1808.6 & 187.1 & 93.0 & 56.6 & 13.7 & 581.7 & 221.3 & 304.7 & 953.0 \\
\hline & 2002 & 1744.5 & 172.1 & 94.0 & 52.2 & 13.3 & 576.1 & 211.7 & 234.1 & 941.9 \\
\hline \multicolumn{11}{|c|}{ LEVEL OF EDUCATION OF THE HEAD-OF-HOUSEHOLD } \\
\hline Not completed & 1990 & 2477.0 & 286.6 & 118.2 & 67.2 & 18.5 & 628.5 & 289.0 & 319.2 & 1002.8 \\
\hline \multirow[t]{2}{*}{ primary school } & 1998 & 2486.7 & 282.7 & 118.1 & 70.9 & 18.5 & 679.6 & 294.1 & 316.7 & 1075.1 \\
\hline & 2002 & 2387.0 & 258.2 & 121.9 & 68.3 & 17.9 & 689.9 & 284.7 & 295.5 & 1083.8 \\
\hline \multirow[t]{3}{*}{ Primary School } & 1990 & 2142.4 & 231.5 & 104.8 & 63.0 & 15.3 & 619.3 & 254.0 & 333.7 & 929.2 \\
\hline & 1998 & 2047.7 & 215.8 & 103.4 & 63.2 & 14.8 & 628.6 & 244.9 & 323.3 & 953.6 \\
\hline & 2002 & 2067.8 & 207.9 & 110.9 & 60.9 & 14.6 & 645.2 & 242.7 & 287.6 & 990.1 \\
\hline \multirow[t]{3}{*}{ Secondary Sch. } & 1990 & 1681.5 & 177.1 & 82.6 & 54.6 & 12.4 & 570.5 & 212.7 & 300.5 & 829.2 \\
\hline & 1998 & 1624.9 & 170.7 & 82.4 & 51.1 & 12.0 & 549.3 & 201.5 & 263.5 & 810.5 \\
\hline & 2002 & 1739.0 & 175.3 & 92.3 & 51.6 & 12.3 & 552.9 & 207.8 & 240.1 & 844.0 \\
\hline \multirow[t]{3}{*}{ High School } & 1990 & 1626.7 & 160.2 & 85.5 & 50.9 & 12.4 & 552.5 & 201.9 & 309.5 & 909.3 \\
\hline & 1998 & 1454.7 & 150.7 & 72.3 & 48.6 & 11.2 & 567.5 & 189.8 & 256.8 & 829.2 \\
\hline & 2002 & 1414.5 & 141.2 & 73.6 & 47.2 & 11.2 & 584.5 & 188.8 & 221.6 & 855.2 \\
\hline
\end{tabular}




\begin{tabular}{|c|c|c|c|c|c|c|c|c|c|c|}
\hline & & $\begin{array}{c}\text { CALORIES } \\
\text { (KCAL) }\end{array}$ & $\begin{array}{c}\text { CARBOHY- } \\
\text { DRATES (GR) }\end{array}$ & $\begin{array}{l}\text { LIPIDS } \\
(\mathrm{GR})\end{array}$ & $\begin{array}{l}\text { PROTEINS } \\
(\mathrm{GR})\end{array}$ & $\begin{array}{l}\text { FIBRE } \\
\text { (GR) }\end{array}$ & $\begin{array}{l}\text { CALCIUM } \\
\text { (MG) }\end{array}$ & $\begin{array}{l}\text { MINERALS } \\
(\mathrm{MG})\end{array}$ & $\begin{array}{c}\text { CHOLES- } \\
\text { TEROL (MG) }\end{array}$ & $\begin{array}{l}\text { VITAMINS } \\
(\mathrm{MG})\end{array}$ \\
\hline \multicolumn{11}{|c|}{ AGE OF THE HEAD-OF-HOUSEHOLD (YEARS) } \\
\hline \multirow[t]{3}{*}{ From 18 to 25} & 1990 & 1470.2 & 173.0 & 65.7 & 46.7 & 10.5 & 423.0 & 182.2 & 272.5 & 628.6 \\
\hline & 1998 & 1382.1 & 158.1 & 64.6 & 46.0 & 11.0 & 464.8 & 181.3 & 245.2 & 770.9 \\
\hline & 2002 & 1277.4 & 165.1 & 53.5 & 41.9 & 9.8 & 480.5 & 167.4 & 214.1 & 640.7 \\
\hline \multirow[t]{3}{*}{ From 26 to 45} & 1990 & 1670.2 & 185.6 & 79.9 & 51.1 & 12.0 & 521.1 & 204.6 & 265.9 & 735.9 \\
\hline & 1998 & 1528.8 & 167.9 & 73.8 & 49.5 & 10.8 & 515.8 & 189.7 & 246.4 & 705.2 \\
\hline & 2002 & 1473.5 & 158.9 & 72.9 & 46.5 & 10.4 & 516.2 & 183.6 & 208.7 & 713.5 \\
\hline \multirow[t]{3}{*}{ From 46 to 65} & 1990 & 2325.0 & 254.9 & 113.4 & 67.0 & 16.9 & 644.5 & 274.8 & 354.2 & 1004.4 \\
\hline & 1998 & 2166.5 & 236.2 & 106.7 & 65.3 & 15.9 & 651.8 & 260.5 & 320.4 & 993.5 \\
\hline & 2002 & 2060.1 & 209.1 & 109.5 & 60.7 & 14.9 & 614.7 & 244.4 & 282.4 & 982.0 \\
\hline \multirow[t]{3}{*}{ More than 65} & 1990 & 2669.9 & 290.6 & 132.7 & 73.5 & 20.0 & 715.2 & 311.0 & 363.4 & 1173.0 \\
\hline & 1998 & 2622.5 & 274.5 & 133.8 & 75.2 & 19.8 & 740.1 & 307.2 & 369.6 & 1245.6 \\
\hline & 2002 & 2617.1 & 264.2 & 142.0 & 73.2 & 19.3 & 792.5 & 305.0 & 334.1 & 1258.1 \\
\hline \multicolumn{11}{|c|}{ HOUSEHOLD COMPOSITION: \% OF MEMBERS OVER 13} \\
\hline \multirow[t]{3}{*}{$25 \%-50 \%$} & 1990 & 1415.1 & 173.2 & 60.6 & 47.1 & 10.6 & 514.5 & 187.1 & 232.3 & 647.0 \\
\hline & 1998 & 1413.0 & 163.7 & 63.2 & 51.0 & 9.8 & 505.3 & 184.7 & 224.8 & 607.0 \\
\hline & 2002 & 1242.4 & 141.8 & 57.4 & 42.2 & 8.5 & 476.2 & 162.3 & 189.9 & 559.0 \\
\hline \multirow[t]{3}{*}{$50 \%-75 \%$} & 1990 & 1609.3 & 183.2 & 74.8 & 50.2 & 11.8 & 512.2 & 201.6 & 263.0 & 703.8 \\
\hline & 1998 & 1450.4 & 160.9 & 69.5 & 47.5 & 10.2 & 517.8 & 182.0 & 240.7 & 664.7 \\
\hline & 2002 & 1438.1 & 156.4 & 71.2 & 45.4 & 10.2 & 504.4 & 180.0 & 201.2 & 673.9 \\
\hline \multirow[t]{3}{*}{ More than $75 \%$} & 1990 & 2415.7 & 261.6 & 119.7 & 68.3 & 17.6 & 657.1 & 282.1 & 354.1 & 1050.3 \\
\hline & 1998 & 2250.8 & 241.3 & 112.4 & 66.8 & 16.7 & 660.3 & 268.1 & 328.7 & 1052.6 \\
\hline & 2002 & 2179.3 & 221.8 & 116.0 & 63.3 & 15.9 & 663.9 & 257.7 & 292.3 & 1050.8 \\
\hline
\end{tabular}

Source: Own elaboration from the Spanish Continuous Survey of Family Budgets (Encuesta Continua de Presupuestos Familiares, ECPF) (several years), conversion factors published in Andújar et.al. (1983) and MAPA (1999). 


\section{APPENDIX B: Derivation of a logarithmic differential form for Equation 5}

Let us start by obtaining the logarithmic differential of Equation 5:

$$
d \ln q_{i}=\eta_{i} d \ln x+\sum_{j=1}^{n} \mu_{i j} d \ln p_{j}+\sum_{j=1}^{n} \sum_{k=1}^{r}\left(\frac{\partial \ln q_{i}}{\partial \ln a_{j k}}\right) d \ln a_{j k}
$$

where $\eta_{i}$ is the income elasticity of demand for good $i$; $\mu_{i j}$ are the uncompensated price elasticities; and $\frac{\partial \ln q_{i}}{\partial \ln a_{j k}}$ is the elasticity of demand for good $i$ with respect to attribute $k$ for food item $j$.

Taking into account that the Slutsky equation is also valid for the present approach, substituting in (A1) the term $\mu_{i j}$ with $\mu_{i j}=e_{i j}-\eta_{i} w_{j}$, we get:

$$
d \ln q_{i}=\eta_{i}\left(d \ln x-\sum_{j=1}^{n} w_{j} d \ln p_{j}\right)+\sum_{j=1}^{n} e_{i j} d \ln p_{j}+\sum_{j=1}^{n} \sum_{k=1}^{r}\left(\frac{\partial \ln q_{i}}{\partial \ln a_{j k}}\right) d \ln a_{j k}
$$

where the $e_{i j}$ represent the compensated price elasticities.

Next, multiplying both sides of (A2) by $w_{i}$ :

$$
w_{i} d \ln q_{i}=\theta_{i}\left(d \ln x-\sum_{j=1}^{n} w_{j} d \ln p_{j}\right)+\sum_{j=1}^{n} \pi_{i j} d \ln p_{j}+\sum_{j=1}^{n} \sum_{k=1}^{r} w_{i}\left(\frac{\partial \ln q_{i}}{\partial \ln a_{j k}}\right) d \ln a_{j k}
$$

where $\theta_{i}=\mathrm{w}_{\mathrm{i}} \eta_{\mathrm{i}}=\mathrm{p}_{\mathrm{i}} \frac{\partial \mathrm{q}_{\mathrm{i}}}{\partial \mathrm{x}}$ is the marginal budget share and $\pi_{\mathrm{ij}}=w_{i} e_{i j}$ is the Slutsky coefficient.

Finally, using the result obtained in ( $\left.8^{\prime}\right)$, the logarithmic differential version of the model is obtained:

$$
w_{i} d \ln q_{i}=\theta_{i} d \ln Q+\sum_{j=1}^{n} \pi_{i j} d \ln p_{j}+\sum_{j=1}^{n} \sum_{k=1}^{r} \beta_{i j k} d \ln a_{j k}
$$

where $d \ln Q=d \ln x-\sum_{j=1}^{n} w_{j} d \ln p_{j}=\sum_{j=1}^{n} w_{j} d \ln q_{j}$ is the Divisia volume index

$$
\text { and } \beta_{i j k}=-\sum_{j=1}^{n} \pi_{i j} \gamma_{j j k}
$$




\section{ACKNOWLEDGEMENTS}

This study presents partial of the project SECJ2006-02328/ECON, financially supported by the Spanish Ministry of Education.

\section{REFERENCES}

Adrian, J. \& Daniel, R. 1976. Impact of the Socio-economic Factors on Consumption of Selected Food Nutrients in the United States. American Journal of Agricultural Economics 58 (1), 31-38.

Andujar, M. M., Moreiras-Varela, O. \& Gil, F. 1983. Tablas de Composición de Alimentos. Trabajo publicado por el Consejo Superior de Investigaciones Científicas, CSIC. Madrid.

Baltagi, B.H. 1980. On Seemingly Unrelated Regressions With Error Components. Econometrica 48 (6), 1547-1551.

Baltagi, B.H. 2001. Econometric Analysis of Panel Data (2 ${ }^{\mathrm{a}}$ Ed.). John Wiley \& Sons. New York.

Barten, A. P. 1977. The System of Consumer Demand Functions Approach: A Review. Econometrica 45 (1), 23-51.

Ben Kaabia, M., Angulo, A.M. \& Gil, J.M. 2001. Health Information and the Demand for Meat in Spain. European Review of Agricultural Economics 28 (4), 499-517.

Bera, A.K., Sosa-Escudero, W. \& Yoon, M. 2001. Tests for the Error Component Model in the Presence of Local Misspecification. Journal of Econometrics 101 (1), 1-23.

Bewley, R. \& Young, T. 1987. Applying Thiel's Multinomial Extension of the Linear Logit Model to Meat Expenditure Data. American Journal of Agricultural Economics 69 (1), 151-157.

Browning, M. \& Collado, D. 1999. The Response of Expenditures to Anticipated Income Changes: Panel Data Estimates. Working Papers, WP-AD 99-19. Instituto Valenciano de Investigaciones Económicas IVIE. Valencia (Spain).

Brown D.J., \& Schrader, L.F. 1990. Cholesterol Information and Shell Egg Consumption. American Journal of Agricultural Economics 72 (3), 548-555.

Capps, O. Jr. \& Schmitz, J.D. 1991. A Recognition of Health and Nutrition Factors in Food Demand Analysis. Western Journal of Agricultural Economics 16 (1), 21-35.

Chesher, A. 1998. Individual Demands from Household Aggregates: Time and Age Variation in the Composition of Diet. Journal of Applied Econometrics 13 (5), 505-524.

Cowling, K. \& Rayner, A.J. 1970. Price, Quality and Market Share. Journal of Political Economy 78 (6), 1292-1309.

Cox, T.L. \& Wohlgenant, M.K. 1986. Prices and Quality Effects in Cross-Sectional Demand Analysis. American Journal of Agricultural Economics 68 (4), 908-919.

Cramer, J. S. 1973. Interaction of Income and Price in Consumer Demand. International Economic Review 14 (2), 351-363. 
Deaton A., 1988. Quality, Quantity and Spatial Variation of Price. American Economic Review 78 (3), 418-430.

Devaney, B. \& Fraker, T. 1989. The Dietary Impacts of the School Breakfast Program. American Journal of Agricultural Economics 71 (4), 932-948.

Duffy, M. 1987. Advertising and the Inter-Product Distribution of Demand: A Rotterdam Model Approach. European Economic Review 31 (5), 1051-70.

Duffy, M. 1989. Measuring the Contribution of Advertising to Growth in Demand: An Econometric-Accounting Framework. International Journal of Advertising 8 (2), 95110.

Duffy, M. 1990. Advertising and Alcoholic Drink Demand in the U. K.: Some Further Rotterdam Model Estimates. International Journal of Advertising 9 (3), 247-57.

Gao, X.M., Wailes, E.J., Cramer, G.L., 1997a. A Microeconometric Analysis of Consumer Taste Determination and Taste Change for Beef. American Journal of Agricultural Economics 79 (2), 573-582.

Gao, X.M., Richards, T.J. \& Kagan, A. 1997b. A Latent Variable Model of Consumer Taste Determination and Taste Change for Complex Carbohydrates. Applied Economics 29 (12), 1643-1654.

Hausman, J.A. 1978. Specification Tests in Econometrics. Econometrica 46 (6), 1251-1272.

Huang, K.S. 1999. Effects of Food Prices and Consumer Income on Nutrient Availability. Applied Economics 31 (3), 367-380.

INE. Several years. Encuesta Continua de Presupuestos Familiares. Madrid.

Keller, W.J. \& Van Driel, J. 1985. Differential Consumer Demand Systems. European Economic Review 27 (3), 375-390.

Chern, W.S. \& Kim, S. 1999. Alternative Measures of Health Information and Demand for Fats and Oils in Japan. The Journal of Consumer Affairs 33 (1), 92-109.

Kinnucan, H.W., Xiao, H., Hsia, C.J. \& Jackson, J.D. 1997. Effect of Health Information and Generic Advertising on U.S. Meat Demand. American Journal of Agricultural Economics 79 (1), 13-23.

Lancaster, K. 1966. A New Approach to Consumer Theory. Journal of Political Economy 74 (2), 132-157.

Lancaster, K. 1971. Consumer Demand: A New Approach. Columbia University Press, New York.

MAPA (several years). La alimentación en España, Madrid.

Ministerio de Agricultura, Pesca y Alimentación MAPA, 1999. La Alimentación en España. Secretaria General de Alimentación. Madrid.

Nayga, R.M. 1994. Effects of Socioeconomic and Demographic Factors on Consumption of Selected Food Nutrients. Agricultural and Resource Economics Review 23 (2), 171182.

Novales, A. 1997. Econometría. McGraw-Hill, Madrid.

Pollak, R.A. \& Wales, T.J. 1981. Demographic Variables in Demand Analysis. Econometrica 49 (6), 1533-1558. 
Prucha, I.R. 1984. On the Asymptotic Efficiency of Feasible Aitken Estimators for Seemingly Unrelated Regression Models With Error Components. Econometrica 52 (1), 203-207.

Ramezani, C.A. 1995. Determinants of Nutrient Demand: A Nonparametric Analysis. Journal of Agricultural and Resource Economics 20(1), 165-177.

Ramezani, C.A., Rose, D. \& Murphy, S. 1995. Aggregation, Flexible Forms, and Estimation of Food Consumption Parameters. American Journal of Agricultural Economics $77(3), 525-532$.

Rickertsen, K., Kristofersson, D. \& Lothe, S. 2003. Effects of Heath Information on Nordic Meat and Fish Demand. Empirical Economics 28 (2), 249-273.

Subramanian, S. \& Deaton, A. 1996. The Demand for Food and Calories. Journal of Political Economy 104 (1), 133-162.

Theil, H. 1980. System-wide Explorations in International Economics, Input-Output Analysis, and Marketing Research. North Holland. Amsterdam.

Wallace, T.D. \& Hussain, A. 1969. The Use of Error Components Models in Combining Cross-section and Time-series Data. Econometrica 37 (1), 55-72.

White, H. 1980. A Heteroskedasticity Consistent Covariance Matrix Estimator and a Direct Test for Heteroskedasticity. Econometrica 48 (4), 817-838.

Xiao, Y. \& Taylor, J.E. 1995. The Impact of Income Growth on Farm Household Nutrient Intake: A Case Study of a Prosperous Rural Area in Northern China. Economic Development and Cultural Change 43(4), 805-819.

Zellner, A. 1962. An Efficient Method of Estimating Seemingly Unrelated Regressions and Tests for Aggregation Bias. Journal of the American Statistical Association 57 (298), 348-368. 
TABLE 1. EVOLUTION OF AT-HOME NUTRIENT INTAKE STRUCTURE (\%)

\begin{tabular}{|c|c|c|c|c|c|c|c|c|c|c|c|c|}
\hline & & $\begin{array}{l}\text { CEREALS } \\
\text { POTATOES }\end{array}$ & RED MEAT & $\begin{array}{l}\text { WHITE MEAT } \\
\text { AND EGGS }\end{array}$ & FISH & DAIRY & OILS & FRUITS & VEGETABLES & $\begin{array}{l}\text { SUGAR AND } \\
\text { SOFT DRINKS }\end{array}$ & $\begin{array}{l}\text { ALCOHOLIC } \\
\text { BEVERAGES } \\
\end{array}$ & $\overline{\text { TOTAL }}$ \\
\hline \multirow{3}{*}{ Calories } & 1990 & 31.92 & 7.00 & 6.30 & 1.80 & 11.70 & 23.27 & 4.98 & 1.60 & 7.25 & 4.19 & 100 \\
\hline & 1998 & 29.97 & 7.64 & 6.69 & 1.92 & 12.65 & 23.37 & 5.51 & 1.67 & 7.24 & 3.34 & 100 \\
\hline & 2002 & 29.39 & 7.78 & 6.02 & 2.06 & 13.23 & 24.56 & 5.45 & 1.79 & 6.88 & 2.85 & 100 \\
\hline \multirow{3}{*}{ Carbohydrates } & 1990 & 60.40 & - & - & 0.12 & 8.12 & - & 10.93 & 2.31 & 16.26 & 1.87 & 100 \\
\hline & 1998 & 57.86 & - & - & 0.13 & 8.97 & - & 12.24 & 2.47 & 16.71 & 1.61 & 100 \\
\hline & 2002 & 57.53 & - & - & 0.14 & 9.76 & - & 12.44 & 2.74 & 15.97 & 1.41 & 100 \\
\hline \multirow{3}{*}{ Lipids } & 1990 & 3.46 & 14.44 & 10.86 & 1.44 & 16.93 & 52.04 & 0.34 & 0.48 & - & - & 100 \\
\hline & 1998 & 3.07 & 15.18 & 11.06 & 1.53 & 18.04 & 50.28 & 0.36 & 0.48 & - & - & 100 \\
\hline & 2002 & 3.36 & 15.66 & 10.01 & 1.68 & 18.79 & 49.54 & 0.39 & 0.56 & - & - & 100 \\
\hline \multirow{3}{*}{ Proteins } & 1990 & 31.95 & 13.54 & 19.98 & 9.69 & 18.51 & - & 2.24 & 3.75 & - & 0.35 & 100 \\
\hline & 1998 & 28.72 & 14.30 & 20.91 & 9.93 & 19.43 & - & 2.61 & 3.79 & - & 0.33 & 100 \\
\hline & 2002 & 28.30 & 14.60 & 18.99 & 10.60 & 20.60 & - & 2.61 & 4.03 & - & 0.28 & 100 \\
\hline \multirow{3}{*}{ Fibre } & 1990 & 50.77 & - & - & - & - & - & 29.02 & 20.21 & - & - & 100 \\
\hline & 1998 & 47.07 & - & - & - & - & - & 32.20 & 20.73 & - & - & 100 \\
\hline & 2002 & 46.62 & - & - & - & - & - & 31.04 & 22.34 & - & - & 100 \\
\hline \multirow{3}{*}{ Calcium } & 1990 & 10.77 & 0.75 & 4.69 & 2.47 & 62.25 & - & 7.19 & 9.45 & 0.72 & 1.71 & 100 \\
\hline & 1998 & 9.07 & 0.82 & 4.26 & 2.42 & 63.73 & - & 8.56 & 9.00 & 0.69 & 1.46 & 100 \\
\hline & 2002 & 9.01 & 0.79 & 3.72 & 2.45 & 64.77 & - & 7.94 & 9.35 & 0.79 & 1.16 & 100 \\
\hline \multirow{3}{*}{ Minerals } & 1990 & 41.90 & 4.61 & 6.25 & 4.51 & 17.68 & - & 10.59 & 10.49 & 0.29 & 3.68 & 100 \\
\hline & 1998 & 38.51 & 5.04 & 6.68 & 4.74 & 18.72 & - & 12.06 & 10.75 & 0.31 & 3.20 & 100 \\
\hline & 2002 & 37.97 & 5.05 & 6.03 & 4.96 & 19.57 & - & 11.90 & 11.45 & 0.39 & 2.68 & 100 \\
\hline \multirow{3}{*}{ Cholesterol } & 1990 & - & 7.06 & 75.50 & 7.09 & 10.34 & - & - & - & - & - & 100 \\
\hline & 1998 & - & 7.85 & 72.44 & 7.90 & 11.81 & - & - & - & - & - & 100 \\
\hline & 2002 & - & 9.03 & 67.89 & 9.10 & 13.98 & - & - & - & - & - & 100 \\
\hline \multirow{3}{*}{ Vitamins } & 1990 & 6.70 & 1.05 & 9.61 & 3.35 & 22.35 & - & 16.67 & 39.95 & - & 0.33 & 100 \\
\hline & 1998 & 5.41 & 1.20 & 8.54 & 3.32 & 22.61 & - & 19.70 & 38.91 & - & 0.31 & 100 \\
\hline & 2002 & 5.73 & 1.11 & 7.31 & 3.58 & 22.92 & - & 17.82 & 41.26 & - & 0.27 & 100 \\
\hline
\end{tabular}

Source: Own elaboration from the Spanish Continuous Survey of Family Budgets (Encuesta Continua de Presupuestos Familiares, ECPF) (several years). 
TABLE 2. EXPENDITURE AND OWN-PRICE ELASTICITIES AT MEAN VALUES

\begin{tabular}{lcccc}
\hline \multirow{2}{*}{ FOOD PRODUCTS } & \multicolumn{2}{c}{ EXPENDITURE ELASTICITIES } & \multicolumn{2}{c}{ OWN PRICE ELASTICITIES } \\
\cline { 2 - 5 } & With Nutrients & Without Nutrients & With Nutrients & Without Nutrients \\
\hline Cereals and potatoes & $0.84^{* *}$ & $0.87^{* *}$ & $-0.47^{* *}$ & $-1.00^{* *}$ \\
Red meat & $1.12^{* *}$ & $1.02^{* *}$ & $-0.46^{* *}$ & $-0.47^{* *}$ \\
White meat and eggs & $0.90^{* *}$ & $1.09^{* *}$ & $-0.32^{* *}$ & $-1.01^{* *}$ \\
Fish & $0.93^{* *}$ & $0.94^{* *}$ & $-0.28^{* *}$ & $-0.16^{* *}$ \\
Dairy & $0.87^{* *}$ & $0.95^{* *}$ & $-0.49^{* *}$ & $-0.72^{* *}$ \\
Oils & $1.01^{* *}$ & $0.95^{* *}$ & $-0.23^{* *}$ & $-0.19^{* *}$ \\
Fruits & $1.20^{* *}$ & $1.16^{* *}$ & $-0.64^{* *}$ & $-0.83^{* *}$ \\
Vegetables & $1.09^{* *}$ & $1.06^{* *}$ & $-0.42^{* *}$ & $-0.39^{* *}$ \\
Sugar and soft drinks & $0.66^{* *}$ & $0.63^{* *}$ & $-0.17^{* *}$ & $-0.56^{* *}$ \\
Alcoholic beverages & $1.32^{* *}$ & $1.23^{* *}$ & $-0.31^{* *}$ & $-0.30^{* *}$ \\
\hline
\end{tabular}

** Indicates significance at $5 \%$ level. 
TABLE 3. OWN-NUTRIENT ELASTICITIES AT MEAN VALUES

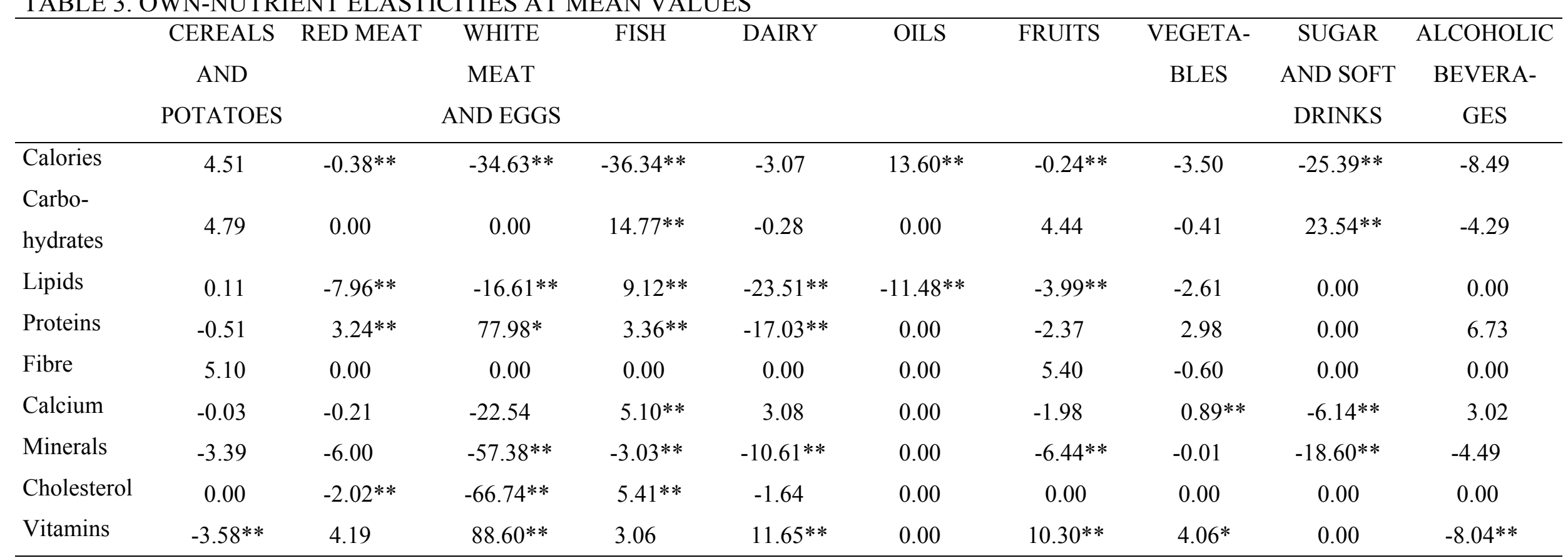

** Indicates significance at 5\% level.

$*$ Indicates significance at $10 \%$ level. 
TABLE 4. EFFECTS OF MAIN SOCIODEMOGRAHIC VARIABLES

\begin{tabular}{llcccccccc}
\hline & $\begin{array}{c}\text { CEREALS } \\
\text { AND } \\
\text { POTATOES }\end{array}$ & $\begin{array}{c}\text { RED } \\
\text { MEAT }\end{array}$ & $\begin{array}{c}\text { WHITE } \\
\text { MEAT } \\
\text { AND EGGS }\end{array}$ & FISH & DAIRY & OILS & FRUITS & $\begin{array}{c}\text { VEGETA } \\
\text { BLES }\end{array}$ & $\begin{array}{c}\text { SUGAR } \\
\text { AND SOFT ALCOHOLIC } \\
\text { DRINKS }\end{array}$ \\
BEVERAGES
\end{tabular}

** Indicates significance at 5\% level. 
